\title{
Kualitas Pelayanan Masyarakat di Kecamatan Bontobahari Kabupaten Bulukumba
}

\author{
Andi Risma Jaya \\ Program Sarjana Ilmu Pemerintahan FISIP \\ Universitas Indonesia Timur Makassar \\ Makassar, Indonesia \\ Email : jayarisma29@gmail.com
}

\begin{abstract}
This study aims to determine the quality of community service in Bontobahari District, Bulukumba Regency, South Sulawesi Province. The method used is descriptive method in order to describe the condition of the subject / object of the researcher based on the facts of the field. The primary data source is obtained from structural officials, officers who are directly faced with the application program users. The data collection technique is done through in-depth interviews, observations, questionnaires and documentation. Based on the results of the research, the quality of community service in Bontobahari Subdistrict is quite good, the procedure that must be followed is quite simple, but there are still some community members who find it difficult to prepare the files. The requirements and completion of the incoming file and meeting our immediate requirements are never postponed. The condition of the facilities and infrastructure of services that are clean, neat and orderly so that they can provide comfort to the recipients of the service. The presence of a technology and and information system in human life today can no longer be circumvented and even its presence is a necessity.
\end{abstract}

Keywords: Service; Service Quality; District

\begin{abstract}
Abstrak
Penelitian ini bertujuan adalah Untuk mengetahui kualitas pelayanan masyarakat di Kecamatan Bontobahari Kabupaten Bulukumba Provinsi Sulawesi Selatan. Metode yang digunakan metode deskriptif agar dapat mendeskripsikan keadaan subyek/obyek peneliti berdasarkan fakta-fakta lapangan. Sumber data primer didapat dari pejabat struktural. Teknik pengumpulan datanya dilakukan melalui wawancara mendalam, observasi, kuesioner dan dokumentasi.Berdasarkan hasil penelitiaan Kualitas pelayanan masyarakat di Kecamatan Bontobahari sudah cukup baik,Prosedur yang harus dijalani cukup sederhana, namun masih ada beberapa anggota masyarakat merasa kesulitan menyiapkan berkas-berkasnya. Persyaratan dan penyelesaikan berkas yang masuk dan memenuhi persyaratan langsung kami proses tidak pernah menunda-menunda. Kondisi sarana dan prasarana pelayanan yang bersih, rapi dan teratur sehingga dapat memberikan rasa nyaman kepada penerima pelayanan. Kehadiran sistem teknologi dan dan informasi dalam kehidupan manusia saat ini tidak dapat lagi dielakan bahkan kehadirannya sudah merupakan kebutuhan.
\end{abstract}

Kata Kunci : Pelayanan; Kualitas Pelayanan; Kecamatan

Link DOI : http://dx.doi.org/10.31314/pjia.7.2.123-128.2018

Copyright @ 2018, Publik : (Jurnal Ilmu Administrasi), ISSN: 2301-573X (Print), ISSN: 2581-2084

(Online) 


\section{PENDAHULUAN}

Pelayanan publik adalah pemenuhan keinginan dan kebutuhan masyarakat oleh penyelenggara negara. Negara didirikan oleh publik (masyarakat) tentu saja dengan tujuan agar dapat meningkatkan kesejahteraan masyarakat. Pada hakikatnya, negara dalam hal ini pemerintah (birokrat) haruslah dapat memenuhi kebutuhan masyarakat. Kebutuhan dalam hal ini bukanlah kebutuhan secara individual, tetapi berbagai kebutuhan yang sesungguhnya diharapkan oleh masyarakat misalnya kebutuhan pendidikan, kesehatan, dan jasa umum lainnya.

Para pemberi pelayanan dituntut tidak hanya memberikan pelayanan standar namun di era kekinian pelayanan prima yang mengedepankan kualitas dibutuhkan untuk memberikan hasil yang lebih baik. Untuk menghasilkan pelayanan yang baik instansi terkait harus mampu memberikan gambaran mengenai kualitas pelayanan kepada para pegawainya baik itu dengan memberikan arahan, mengharuskan membaca pedoman dan memberikan pelatihanpelatihan dalam upaya peningkatan kualitas pegawai itu sendiri (Mohi, WK, Mahmud I, 2018).

Pada dasanya ada beberapa pertimbangan mengapa pelayanan publik menjadi titik starategis untuk memulai pengembangan Good Govermance di Indonesia. Pertama pelayanan public selama ini menjadi ranah dimana negara yang diwakili oleh pemerintah yang berinteraksi dengan lembaga-lembaga non pemerintah. Kedua, pelayanan publik adalah ranah dimana berbagai aspek
Good Govermance dapat diartikulasikan secara .relatif lebih mudah. Ketiga, pelayanan publik melibatkan kepentingan untuk melaksanakan pembaharuan dalam praktek penyelenggaraan pelayanan publik.

Salah satu pelayanan publik yang dilaksanakan oleh kantor Kecamatan Bontobahari Kabupaten Bulukumba adalah pelayanan perizinan dan pelayanan administrasi kependudukan. Misalnya dalam bentuk pelayanan perizinan dan rekomendasi Izin Mendirikan Bangunan (rekomendasi IMB), dan bentuk pelayanan administrasi kependudukan adalah Kartu Tanda Penduduk (KTP) dan Kartu Keluarga (KK).

Secara empirik dan aktual, pelayanan rekomendasi IMB, KTP, dan KK yang diterima oleh masyarakat belum sepenuhnya memuaskan dan memenuhi kebutuhan masyrakat hal ini dapat dilihat dari masih banyaknya keluhan masyarakat yakni biaya pengurusan yang tidak jelas, penyelesaian yang membutuhksan waktu yang lama, dan terkadang izin yang dikeluarkan hamya rekomendasi izin pembangunan, sementara IMBnya sendiri tidak pernah ada selain itu, pemberian rekomendasi IMB banyak menyalahi aturan, sehingga masyarakat harus menanggung akibat keteledoran aparat (pegawai).

Demikain pula untuk pengrusan KTP dan KK, masih adanya pungutan diluar kewajaran biaya dan waktu pengurusan yang terlalu lama dan berteletele, sehingga menyulitkan masyarakat. Aparat dalam hal ini pegawai Kantor Kecamatan Bontobahari Kabupaten Bulukumba sebagai pilar utama 
pelayanan pada masyarakat hendaknya mampu memperlihatkan perilaku yang baik dan bertanggung jawab, sehingga mampu memberikan pelayanan yang terbaik bagi masyarakat yang membutuhkan. Perilaku ini akan tercermin dari sikap, watak dan keyakinan sebagai abdi masyrakat bukan untuk dilayani melainkan melayani. Dengan konsep demikian, maka diharapkan bahwa kualitas pelayanan akan tercipta karena bersumber dan berakar dari perilaku birokrat itu sendiri.

Penelitian ini dipandang perlu karena berupaya menggambarkan peranan birokrasi pemerintahan dalam memberiakan pelayanan kepada masyarakat. Melalui kajian ini, diharapkan dapat ditemukan solusi dalam rangka perbaikan kualitas pelayanan masyarakat oleh Birokrasi Pemerintahan Kecamatan Bontobahari Kabupaten Bulukumba Sulawesi Selatan.Dari uaraian latar belakang di atas, maka dapat dikemukakan rumusan masalah adalah Bagaimana kualitas pelayanan masyarakat di Kecamatan Bontobahari Kabupaten Bulukumba Provinsi Sulawesi Selatan. Berdasarkan uraian diatas maka penelitian ini bertujuan adalah Untuk mengetahui kualitas pelayanan masyarakat di Kecamatan Bontobahari Kabupaten Bulukumba Provinsi Sulawesi Selatan

\section{METODE PENELITIAN}

Pendekatan yang digunakan dalam penelitian ini adalah pendekatan kualitatif, sedangkan jenis penelitian yang digunakan adalah penelitian diskriptif yaitu penelitian yang dilakukan untuk menggambarkan bagaimana kualitas pelayanan pada kantor Camat Bonto Bahari Kabupaten Bulukumba

Metode yang digunakan metode deskriptif agar dapat mendeskripsikan keadaan subyek/obyek peneliti berdasarkan fakta-fakta lapangan. Sumber data primer didapat dari pejabat struktural, petugas yang langsung berhadapan dengan pengguna program aplikasi. Teknik pengumpulan datanya dilakukan melalui wawancara mendalam, observasi, kuesioner dan dokumentasi.

\section{HASIL DAN PEMBAHASAN}

Kualitas Pelayanan Masyarakat Di Kecamatan Bontobahari Kabupaten Bulukumba Provinsi Sulawesi Selatan

1. Prosedur Pelayanan

Tabel 1 Pendapat Responden Terhadap Kemudahan Prosedur Pelayanan di Kantor Kecamatan Bontobahari

\begin{tabular}{llll}
\hline No & $\begin{array}{l}\text { Jawaban } \\
\text { Responden }\end{array}$ & Frekuensi & $\begin{array}{l}\text { Persentase } \\
(\%)\end{array}$ \\
\hline 1 & $\begin{array}{l}\text { Sangat } \\
\text { Mudah }\end{array}$ & 1 & 5 \\
2 & Mudah & 10 & 50 \\
3 & Sukar & & 45 \\
& & 9 & 100 \\
Jumlah & 20 &
\end{tabular}

Sumber : Data Primer, 2012

Dari tabel 1 menunjukkan bahwa dari 20 respon, 1 orang atau $5 \%$ responden menjawab sangat mudah, dan 10 orang atau $50 \%$ responden menjawab mudah, sedangkan 9 orang atau $45 \%$ responden menjawab sukar.

Pernyataan salah seseorang responden (ANF) yang mengaku bahwa : 
Prosedur yang harus dijalani masih sukar dan menyulitkan karena berkas-berkas yang harus dilengkapi pembangunan yang dibuktikan dengan gambar lokasi dan bangunan serta keterangan mengenai pemilikan atau penguasaan, jadi cukup banyak kemudian terlalu belit-belit. (wawancara dengan responden, tanggal 22 Februari 2012 ).

\section{Kesusaian Prasyarat}

Tabel 2 Pendapat Responden terhadap Kesesuian Prasyarat Pelayanan di Kantor Kecamatan Bontobahari

\begin{tabular}{llrc}
\hline No & $\begin{array}{l}\text { Jawaban } \\
\text { Responden }\end{array}$ & Frekuensi & $\begin{array}{l}\text { Persentase } \\
(\%)\end{array}$ \\
\hline 1 & $\begin{array}{l}\text { Sangat } \\
\text { Sesuai }\end{array}$ & 11 & 55 \\
2 & Sesuai & 7 & 35 \\
3 & $\begin{array}{l}\text { Kurang } \\
\text { Sesuai } \\
\text { Jumlah }\end{array}$ & 20 & 10 \\
& & 100
\end{tabular}

Sumber : Data Primer, 2012

Dari tabel 2 menunjukkan bahwa dari 20 responden, 11 orang atau 55\% responden menjawab sangat sesuai, dan 7 orang atau 35\% responden menjawab sesuai, sedangkan 3 orang atau $10 \%$ responden menjawab kurang sesuai. Rata-rata pendapat responden terhadap persyaratan pelayanan adalah sangat sesuai dengan jenis pelayanan yang ada di Kantor Kecamatan Bontobahari. Hal ini didukung pernyataan salah seorang responden (MJr) mengatakan bahwa : Persyaratan yang ditetapkan untuk mengurus rekomendasi sudah sesuai dengan jenis pelayanan. Kami harus melengkapi administrasi dan mengisi formulir persyaratan sesuai jenis pelayanan yang diberikan. (wawancara dengan responden, tanggal 22 Februari 2012).

\section{Sarana dan Prasana}

Tabel 3 Pendapat Responden terhadap Kenyaman Lingkungan yang Ditunjang oleh Sarana dan Prasana

\begin{tabular}{llll}
\hline No & $\begin{array}{l}\text { Tanggapan } \\
\text { Responden }\end{array}$ & Frekuensi & $\begin{array}{l}\text { Persentase } \\
(\%)\end{array}$ \\
\hline 1 & Nyaman & 13 & 65 \\
2 & $\begin{array}{l}\text { Cukup } \\
\text { Nyaman }\end{array}$ & 5 & 25 \\
3 & $\begin{array}{l}\text { Kurang } \\
\text { Nyaman }\end{array}$ & 10 \\
Jumlah & 20 & 100 \\
\hline
\end{tabular}

Sumber : Data Primer, 2012

Dari uraian Tabel 3 menunjukkan bahwa 20 responden, 13 orang atau $65 \%$ responden menjawab nyaman dan 5 orang atau $25 \%$ responden menjawab cukup nyaman sedangkan 2 orang atau $10 \%$ responden menjawab kurang nyaman. Hal ini diperkuat ioleh pernyataan salah seorang responden $(\mathrm{Uj})$ : Ruangan pelayanannya sempit, begitu pula dengan tempat antri, sehingga terkadang kami harus menunggu di luar untuk mengantri pelayanan, kalau ruangannya memang bersih dan rapi namun sempit. (wawancara dengan responden tanggal 22 Februari 2012).

\section{Sistem Teknologi dan Informasi}

Seperti yang diungkapkan oleh responden (Arj) bahwa :Ketika saya 
mengurus data penelitian, pada saat itu file data tidak ada didalam komputer, jadi saya menunggu tanpa ada kepastian informasi dan ternyata dokumennya dibawah pulang oleh pegawai Kecamatan dirumahnya. (wawancara dengan responden tanggal 22 Februari 2012).

\section{PENUTUP}

\section{Kesimpulan}

Berdasarkan hasil penelitiaan Kualitas pelayanan masyarakat di Kecamatan Bontobahari sudah cukup baik, penyedia pelayanan publik perlu melakukan langkah strategis penataan kualitas pelayanan publik secara prima yang cepat, pasti, mudah, biaya yang layak, transparan, akuntabel, dengan program perbaikan manejemen, sistem, ketentuan perundang-undangan, prosedur serta aparat pelayanan publik, dan pencegahanpraktekmenyimpang prosedur pelayanan, dengan indikator-indikator sebagai berikut :

Prosedur yang harus dijalani cukup sederhana, namun masih ada beberapa anggota masyarakat merasa kesulitan menyiapkan berkas-berkasnya. Meskipun demikian, mereka tetap menyelesaikan berkas walau dalam waktu yang cukup lama. Kondisi tidak diharapkan, baik oleh pihak pemberi jasa layanan karena prosedur tersebut akan menghambat kelancaran proses pelayanan.

Persyaratan dan penyelesaikan berkas yang masuk dan memenuhi persyaratan langsung kami proses tidak pernah menunda-menunda. Walaupun berkas yang terlambat dalam penyelesaian, tapi kemungkinannya berkaitan hal-hal teknis. Kondisi sarana dan prasarana pelayanan yang bersih, rapi dan teratur sehingga dapat memberikan rasa nyaman kepada penerima pelayanan. Kehadiran sistem teknologi dan dan informasi dalam kehidupan manusia saat ini tidak dapat lagi dielakan bahkan kehadirannya sudah merupakan kebutuhan sangat Penting.

\section{DAFTAR PUSTAKA}

Dwiyanto dkk. (2002). Membangun Sistem Pelayanan Publik yang Memihak pada Rakyat. Pusat penelitian dan Studi Kependudukan. UGM : Yogyakarta.

Gaspersz. (2004). Perencanaan Strategik sector publik. Jakarta: Gramedia Pustaka Utama.

Gibson, dkk. (1997). Organisasi. Perilaku, Struktur, Proses. Jakarta :Erlangga

Ivancevich, Lorenzi, Skinner \& Crosby. (1997). Management Quality and Competitiveness (second edition). Chicago: Mirwin. Kurniawan. Agung. (2005).

Transformasi Pelayanan Publik. Yogyakarta: Pembauran.

Lukman, Sampara, (2000). Manejemen Kualitas Pelayanan. Jakarta : STIA-LAN Press.

Mohi, W. K., \& Mahmud, I. (2018). Kualitas Pelayanan Publik di Desa Potanga Kecamatan Boliyohuto Kabupaten Gorontalo. Publik (Jurnal Ilmu Administrasi), 6(2), 102-110.

Robbins, S.P. (2006). Teori Organisasi: Struktur, Desain, \& Aplikasi. Ahli Bahasa: yusuf udaya. Jakarta : Arcan 
Sartono. (2004). Memahami Good

Governance Dalam Perspektif

Sumber Daya Manusia.

Yogyakarta: Gava Media.

Sinambela dkk. (2006). Reformasi

Pelayanan Publik, Teori,

Kebijakan, dan Implementasi.

Jakarta: Bumi Aksara

Soeling PO. (1997). Pemberdayaan

SDM untuk Peningkatan

Pelayanan dalam Bisnis

Birokrasi. Jakarta : Bumi Aksara

Strong C.F. (1966). Modern Political

Consitution. The English Book

Society and Sidgwick \&

Jackson Ltd London.

Warella. (1997). Administrasi dan

Kualitas Pelayanan Publik.

Jurnal Ilmu Administrasi Dan

Kebijakan Publik. Semarang.

MAP UNDIP. 